\title{
PRELIMINARY ASSESSMENT OF THE DISTRIBUTION OF PM2.5-BOUND POLYCYCLIC AROMATIC HYDROCARBONS IN PRIMARY SCHOOL ENVIRONMENTS IN KUALA LUMPUR
}

\author{
MOHAMAD FIRDAUS ISMAIL ${ }^{1}$, MUHAMMAD FAIS FADZIL ${ }^{2}$, NORHAYATI MOHD TAHIR ${ }^{1,2}$, MOHD \\ TALIB LATIF ${ }^{3}$, AND NOORLIN MOHAMAD $^{1 *}$ \\ ${ }^{1}$ School of Marine and Environmental Sciences, Universiti Malaysia Terengganu, 21030 Kuala Nerus, \\ Terengganu \\ ${ }^{2}$ Institute of Oceanography and Environment (INOS), Universiti Malaysia Terengganu, 21030 Kuala Nerus, \\ Terengganu \\ ${ }^{3}$ School of Environmental Science and Natural Resources, Faculty of Science and Technology, Universiti \\ Kebangsaan Malaysia, 43600 Bangi, Selangor
}

${ }^{*}$ Corresponding author: noorlin@umt.edu.my

\begin{abstract}
Fine particulate matter (aerodynamic diameter $\leq 2.5 \mu \mathrm{m})\left(\mathrm{PM}_{2.5}\right)$ has become a major concern because it can adsorb chemicals e.g. polycyclic aromatic hydrocarbons (PAHs) onto its surface. Although PAHs are priority pollutants that can cause adverse health effect, there is still limited information concerning indoor exposures to PAHs in Malaysia. This study aimed to characterise the distribution of PAHs bounded to $\mathrm{PM}_{2.5}$ in primary school environments. Indoor and outdoor $\mathrm{PM}_{2.5}$ were collected between May and July 2017 using low volume samplers (LVS) at three public primary schools in the Federal Territory of Kuala Lumpur. PAHs were extracted by ultrasonic extraction with Dichloromethane: nHexane $(1: 1, \mathrm{v} / \mathrm{v})$ as the extraction solvent and analysed using gas chromatography coupled with mass spectrometer (GC-MS). Based on the results, the average total concentration of PAHs ( $\sum$ PAHs) ranged from 3.8 to $10.1 \mathrm{ng} \mathrm{m}^{-3}$ and 1.6 to $8.0 \mathrm{ng} \mathrm{m}^{-3}$ for outdoors and indoors, respectively. PAHs in $\mathrm{PM}_{2.5}$ samples indicated the potential contribution of combustion at high temperature and indoor sources and the infiltration of outdoor PAHs were the important sources for outdoor and indoor, respectively. In addition, the diagnostic ratio analysis showed that vehicular emissions were the most predominant sources of PAHs in school environments.
\end{abstract}

Keywords: $\mathrm{PM}_{2.5}$, polycyclic aromatic hydrocarbons (PAHs), school, indoor, outdoor, vehicular emission

\section{Introduction}

Polycyclic aromatic hydrocarbons or commonly referred to as PAHs are organic compound that consist of two or more fused aromatic rings of carbon and hydrogen (Abdel-Shafy \& Mansour, 2016). PAHs have been classified as persistent organic pollutants (POPs) due to their ability to resist environmental degradation through biological, chemical, and photolytic processes. According to the United States Environmental Protection Agency (USEPA), there are 16 PAHs that have been classified as priority pollutants due to their known toxicity. These 16 compounds are Naphthalene (Nap), Acenaphthylene (Ace), Acenaphthene (Acp), Flourene (Flo), Phenanthrene (Phe), Anthracene (Ant), Fluoranthene (Flu), Pyrene (Py), Benzo(a)anthracene (BaA), Chrysene (Chr), Benzo(b)fluoranthene (BbF), Benzo(k)fluoranthene (BkF), Benzo(a)pyrene (BaP), Indino(1,2,3-cd)pyrene (Ind), Benzo(g,h,i)perylene (BghiP), Dibenzo(a,h)anthracene (DBA) (USEPA, 2008). Both China and the United States Environmental Protection Agency have identified that seven out of the 16 PAHs are potential carcinogenic (Chai et al., 2007).

PAHs in the environment have a tendency to accumulate in the atmosphere, mainly via adsorption onto particulate matter (Kim et al., 2013). According to Omar et al. (2002), combustion sources are the reason behind the abundance of PAHs in the global environment especially in urban areas where the concentration is even higher. Several combustion-related activities that contribute greatly to the occurrence of PAHs in outdoor air are petrol, coal, diesel and gasoline combustion (Kim et al., 2013; Xu et al., 2016). Aside from these anthropogenic sources, natural sources such as forest fire also contributes to the increased concentration of PAHs in the environment (Barro et al., 2009).

In indoor air, sources of PAHs include tobacco smoke, cooking, the uses of the heating system, and the building materials used (Mannino \& Orrechio, 2008; Romagnoli et al., 2014). For school environment, the most common sources of PAHs that are related to indoor activities are the use of petroleum-based artistic materials (paints, crayons and clays), burning of candles (birthday celebration) as well as the use of cleaning materials (Oliveira et al., 2016; 2017). However, the rate of indoor and outdoor pollutant exchange, the rate of surface scavenging, chemical reaction involved in indoor environment as well as the removal of pollutants through ventilation or filtration also contribute to the concentration of indoor PAHs (Romagnoli et al., 2014).

The carcinogenicity and the non-existent threshold value of PAHs dose-response relationship have made PAHs unsafe at any levels (Omar et al., 2006). Due to 
their widespread distribution, particularly in the atmosphere, PAHs are threats to vulnerable groups of the population especially children in urban environment. Therefore, the aim of this study is to characterize the distribution of PAHs bounded to $\mathrm{PM}_{2.5}$ in school environments in Kuala Lumpur, Malaysia.

\section{Materials and Methods \\ PM2.5 Sampling}

$\mathrm{PM}_{2.5}$ sampling was conducted in the indoor and outdoor environments of three primary schools located in the Federal Territory of Kuala Lumpur between May and July 2017. The characteristics of each school are listed in Table 1. Indoor and outdoor samplings were conducted simultaneously for three consecutive school days at each school using two identical low volume samplers, LVS (Airmetric MiniVol Portable Air Sampler, United States).

Table 1: Characteristics of the sampling locations

\begin{tabular}{|c|c|c|c|c|}
\hline & & S1 & $\mathbf{S 2}$ & S3 \\
\hline \multicolumn{2}{|l|}{ Floor Level } & First & First & Third \\
\hline \multicolumn{2}{|l|}{ Area $\left(m^{2}\right)$} & 68.37 & 74.18 & 63.70 \\
\hline \multirow{2}{*}{$\begin{array}{l}\text { No. of } \\
\text { Students }\end{array}$} & Morning & 34 & 27 & 30 \\
\hline & Afternoon & - & - & 29 \\
\hline \multirow{5}{*}{$\begin{array}{l}\text { Type of } \\
\text { facilities }\end{array}$} & Chair & Wood & Wood & Wood \\
\hline & Desk & Wood & Wood & Wood \\
\hline & Cupboard & Metal & Metal & Metal \\
\hline & Board & Whiteboard & Whiteboard & Whiteboard \\
\hline & Curtain & Mixa & Cotton & Cotton \\
\hline Floor & Materials & Cement & Vinyl & Cement \\
\hline \multicolumn{2}{|l|}{ Wear Shoes } & Yes & No & Yes \\
\hline \multicolumn{2}{|c|}{ Ventilation System } & Natural & Natural & Natural \\
\hline \multirow{3}{*}{\multicolumn{2}{|c|}{ School Location }} & $\begin{array}{l}\text { Business centre } \\
\text { and near to the }\end{array}$ & $\begin{array}{l}\text { Business } \\
\text { centre }\end{array}$ & Business \\
\hline & & construction site & and near to the & centre area \\
\hline & & & rainforest & \\
\hline
\end{tabular}

For indoor sampling, the sampler was placed inside the classroom at the back, $1 \mathrm{~m}$ off the floor and $6 \mathrm{~m}$ away from the wall. Meanwhile, for outdoor sampling, the sampler was placed about $5 \mathrm{~m}$ away from the classroom building and $1 \mathrm{~m}$ off the ground. Samples were collected onto pre-cleaned quartz fiber filter paper with a diameter of $47 \mathrm{~mm}$ and porosity of $0.45 \mu \mathrm{m}$ for $24 \mathrm{~h}$ by LVS running with the flow rate of $5 \mathrm{~L} \mathrm{~min}^{-1}$. Filter papers were changed each day, kept in a cleaned petri dish and transferred into a desiccator. At the end of the sampling period, a total of 24 samples were collected from three sampling stations. Determination of the blank sample was done by placing the filter paper inside the sampler without turning it on. The filters that had been used for sampling were dried in a desiccator for $48 \mathrm{~h}$ prior to gravimetric analysis.

\section{Sample Extraction and PAHs Analysis}

The method used for the extraction of PAHs from $\mathrm{PM}_{2.5}$ samples was modified from Omar et al. (2002). Prior to the extraction, the pre-weighed filter papers were cut into small pieces (approximately $1 \mathrm{~cm} \times 1 \mathrm{~cm}) .50 \mu \mathrm{l}(100$ $\mathrm{ppm})$ of internal standards consisting of perdeuterated 
phenanthrene $\left(\mathrm{C}_{10} \mathrm{D}_{10}\right)$ and perdeuterated perylene $\left(\mathrm{C}_{12} \mathrm{D}_{12}\right)$ were spiked into the samples for the purpose of recovery assessment. Samples were extracted by ultrasonic extraction for $30 \mathrm{~min}$ with dichloromethane (DCM): n-Hexane (1:1, v/v) as the extraction solvent and the process was repeated three times. The extracted samples were filtered and combined in each designated test tube followed by removal of excess solvent using nitrogen evaporator until they became $100 \mu \mathrm{l}$.

For the purpose of identification and quantification of PAHs for both indoor and outdoor samples, a Shimadzu mass spectrometer integrated with a Shimadzu Gas Chromatography GC-2010 Plus equipped with a SGE; BP5M5 29.7 m fused silica capillary column $(0.25$ mm i.d) coated with $5 \%$ phenyl methyl siloxane with thickness and diameter of $0.25 \mu \mathrm{m}$ and $0.25 \mathrm{~mm}$, respectively, was used. The analysis was done by a splitless mode. Helium gas with a constant pressure of $500 \mathrm{kPa}$ was used as the carrier gas with a column's flow rate of $1.19 \mathrm{~mL} \mathrm{~min}^{-1}$. Before each sample was injected into GC-MS, $1 \mu \mathrm{L}$ of PAHs external standard was injected first. $1 \mu \mathrm{L}$ of each sample was then injected into the column of GC-MS. Gas chromatography produced a result in the form of spectral peak of individual compounds of PAHs that were based on their retention time as well as key fragment ions. The analysis was done using Selective Ion Monitoring (SIM) mode for a better detection. The GC column temperature was programmed as follows: $50{ }^{\circ} \mathrm{C}$ for $1 \mathrm{~min}, 50$ to $140{ }^{\circ} \mathrm{C}$ at $5{ }^{\circ} \mathrm{C} \mathrm{min}-$ ${ }^{1}, 140$ to $300{ }^{\circ} \mathrm{C}$ at $4^{\circ} \mathrm{C} \mathrm{min}^{-1}$ and followed by isothermal period for $15 \mathrm{~min}$ at $300^{\circ} \mathrm{C}$.

\section{Recovery and Method Detection Limit}

In order to minimize both the sampling and measurement errors, the quality controls were carried out by using field blanks, procedural blanks, surrogate recoveries and standard spike recovery. Field blanks were obtained by placing the Quartz filter paper inside LVS without turning it on. The procedural blank was prepared for each batch of sample extraction using a set of blank solvent. This procedure blank underwent the same process as the sample. Both internal and external standards were used for the purpose of recoveries and quantification. The percentage recovery ranged from 68.47 to $105.39 \%$. The limit of detection (LOD) for individual PAHs compound ranged from 0.01 to $0.23 \mathrm{ng} \mathrm{m}^{-3}$.

\section{Results and Discussion \\ Concentration of PM2.5 in Indoor and Outdoor School Environment}

The descriptive statistics of $24 \mathrm{~h}$ indoor and outdoor $\mathrm{PM}_{2.5}$ concentrations measured at three schools, S1, S2, and S3, are presented in Table 2. The concentration of indoor $\mathrm{PM}_{2.5}$ ranged from $13.89 \mu \mathrm{g} \mathrm{m}^{-3}$ (minimum) to $83.33 \mu \mathrm{g} \mathrm{m}^{-3}$ (maximum) with the mean value between 27.78 to $60.19 \mu \mathrm{g} \mathrm{m}^{-3}$ for each school. The concentration of outdoor $\mathrm{PM}_{2.5}$ ranged from 13.89 to $69.44 \mu \mathrm{g} \mathrm{m}^{-3}$ and the $\mathrm{PM}_{2.5}$ mean value in ambient air for each school was between 41.67 and $50.93 \mu \mathrm{g} \mathrm{m}^{-3}$.

Table 2: Descriptive statistics of $24 \mathrm{~h}$ mean indoor and outdoor $\mathrm{PM}_{2.5}\left(\mu \mathrm{g} \mathrm{m}^{-3}\right)$

\begin{tabular}{|c|c|c|c|c|c|c|}
\hline & \multicolumn{3}{|c|}{ Indoor $(n=3)$} & \multicolumn{3}{|c|}{ Outdoor $(n=3)$} \\
\hline & Min & Max & Avg \pm SD & Min & Max & Avg \pm SD \\
\hline $\mathrm{S} 1$ & 13.89 & 55.56 & $27.78 \pm 24.06$ & 13.89 & 55.56 & $41.67 \pm 24.05$ \\
\hline S2 & 13.89 & 41.67 & $27.78 \pm 13.89$ & 27.78 & 69.44 & $41.67 \pm 24.05$ \\
\hline S3 & 27.78 & 83.33 & $60.19 \pm 28.91$ & 41.67 & 55.56 & $50.93 \pm 8.02$ \\
\hline
\end{tabular}

The highest concentration of indoor $\mathrm{PM}_{2.5}$ was recorded in $\mathrm{S} 2$ and outdoor $\mathrm{PM}_{2.5}$ in $\mathrm{S} 3$. Both $\mathrm{S} 2$ and $\mathrm{S} 3$ were located near a business centre and close to the main road. The presence of vehicular emission in the surrounding area might contribute to the high concentration of $\mathrm{PM}_{2.5}$. Similar observation was obtained in previous studies in which the sampling location shared similar profile e.g. located in an urban area and near the main road, such as in Selangor by Othman et al. (2016) and Khan et al. (2016). Moreover, the direct interaction between the sources of $\mathrm{PM}_{2.5}$, in this case from vehicular emission, possibly led to the increase in the outdoor $\mathrm{PM}_{2.5}$ concentrations, which was in agreement with the finding of previous studies by Othman et al. (2016) in Selangor and Amil et al. (2016) in Klang Valley.

\section{Total PAHs Distribution}

In this study, the total PAHs concentration ( $\sum \mathrm{PAHs}$ ) referred to the sum of the concentrations of 18 individual PAHs (16 USEPA priority PAHs + Benzo[e]pyrene and Perylene). The average $\sum$ PAHs concentration for S1, S2, and S3 are presented in Figure 1. The range of $\sum$ PAHs obtained for outdoors and indoors was from 3.8 to 10.1

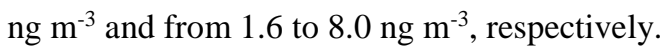




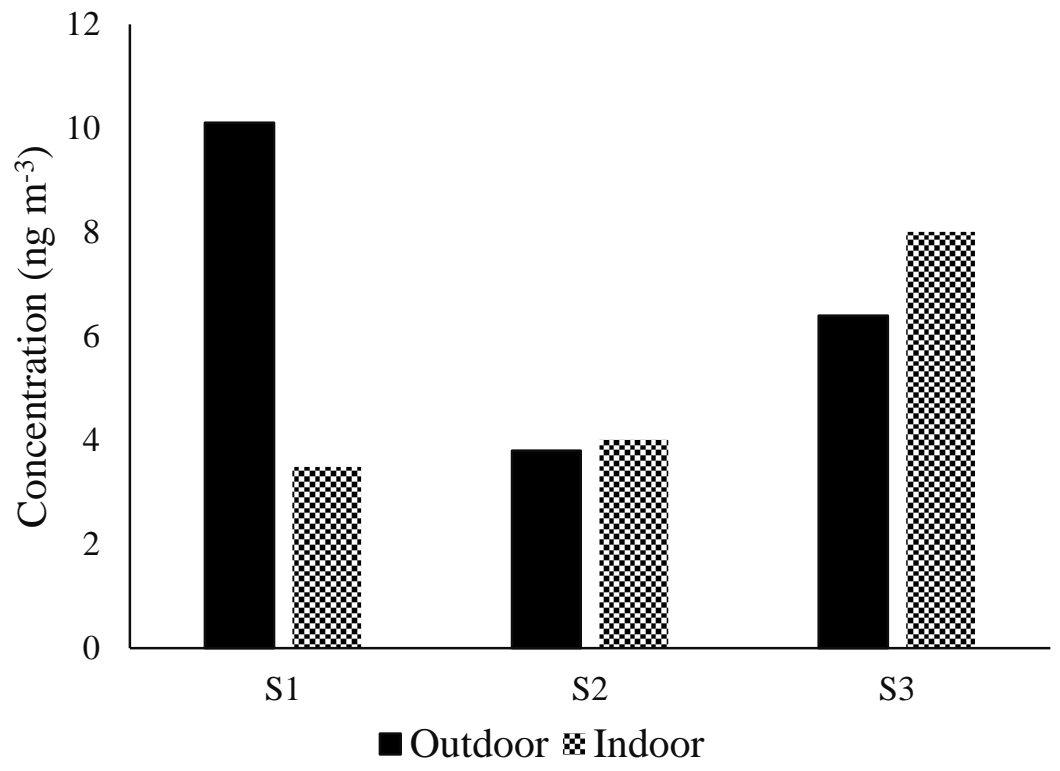

Figure 1: Average concentration of $\sum$ PAHs in outdoor and indoor environment

Based on the results, there was no visible pattern in the distribution of $\sum$ PAHs in outdoor and indoor environment. In $\mathrm{S} 1$, outdoor $\sum \mathrm{PAHs}$ was higher compared to indoor. S2 on the other hand showed similar distribution between outdoor and indoor $\sum$ PAHs. However, in S3, the concentration of $\sum$ PAHs was higher in indoor environment. For outdoor $\sum \mathrm{PAHs}$, the highest concentration was recorded at $\mathrm{S} 1\left(10.1 \mathrm{ng} \mathrm{m}^{-3}\right)$ and the lowest at $\mathrm{S} 2\left(3.8 \mathrm{ng} \mathrm{m}^{-3}\right)$. S1 is surrounded by business areas and construction sites, and less than $50 \mathrm{~m}$ away from the main road. Therefore, the traffic emission in the surrounding areas, for instance, from heavy machinery at the construction site and vehicles from the main road, might contribute to the high concentration of $\sum$ PAHs.

The lowest outdoor $\sum$ PAHs was recorded in S2. S2 was located near the city centre of Kuala Lumpur but surrounded by reserved forest. The low $\sum$ PAHs obtained was probably due to less traffic densities in that area. This finding was in agreement with previous studies such as Jamhari et al. (2014), Hassanvand et al. (2015) that showed low traffic densities did not lead to low $\sum$ PAHs obtained. Moreover, the presence of the surrounding forest that acts as a natural filter contributes to the removal of air pollutants, thus lowering the concentration of total $\sum$ PAHs. The finding from the current study was in agreement with the reported results by Hamid et al. (2017) in Selangor and Malacca.

Indoor $\sum$ PAHs was recorded highest at $\mathrm{S} 3(8.0 \mathrm{ng}$ $\mathrm{m}^{-3}$ ) and lowest at $\mathrm{S} 1\left(3.48 \mathrm{ng} \mathrm{m}^{-3}\right)$. S3 is located near a business centre where many anthropogenic sources from nearby business activities e.g. vehicular emission could lead to higher $\sum$ PAHs. Moreover, the sampling in S3 was carried out on the third floor while the samplings in other schools were conducted on the first floor. Jung et al. (2011) found that the increase in floor level (from level one to five) for $\mathrm{PM}_{2.5}$ sampling resulted in a noticeable increase in the concentration of the $\mathrm{PM}_{2.5}$ obtained. This may due to the increase in the infiltration rate of outdoor air into the classrooms.

In addition, indoor $\mathrm{PM}_{2.5}$ concentration also was recorded highest in S3. The Pearson correlation showed a strong positive correlation between indoor $\mathrm{PM}_{2.5}$ and indoor PAHs $(r=0.7243)$ suggesting that higher concentration of $\mathrm{PM}_{2.5}$ leads to higher concentration of $\sum$ PAHs. On the other hand, despite having the highest $\sum$ PAHs recorded for outdoor environment, S1 had the lowest indoor $\sum$ PAHs recorded. This may due to the minimal indoor activities by the occupants and lower infiltration rate of outdoor air into indoor similar to a reported previous finding by Mohammed et al. (2016).

The comparison between $\sum$ PAHs obtained in the present study and previous studies is shown in Table 3 . The results showed that the range for the concentration of $\sum$ PAHs obtained in this study was quite similar to the results obtained by Khan et al. (2016) during southwest monsoon in Kuala Lumpur. Sample collections by Khan et al. (2016) were done between June and September 2015, which was during southwest monsoon. In this study, the samplings were conducted between May and July 2017, which was in the early southwest monsoon. Due to the similarity in terms of sampling period, seasonal behaviours and the sampling location i.e. Kuala Lumpur, the results obtained in both studies showed a similarity in the concentration of $\sum$ PAHs obtained. The literature concerning the level of PAHs bounded in $\mathrm{PM}_{2.5}$ in outdoor and indoor environment in Malaysia is limited to date, causing difficulties to compare the results in the present study with reported previous studies. 
Table 3: Comparison of $\sum$ PAHs obtained from previous studies.

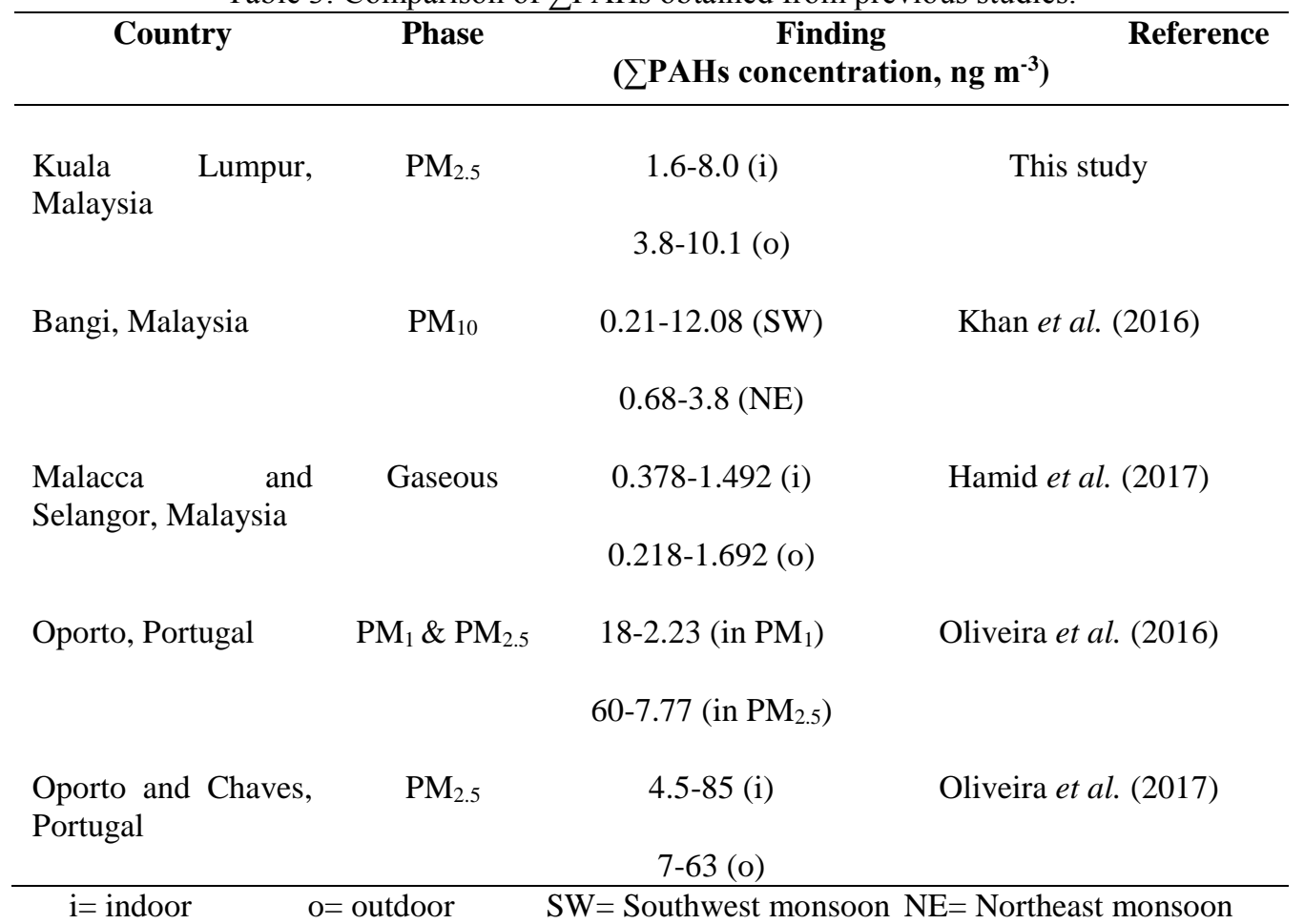

It was found that the range of the concentration of $\sum$ PAHs obtained in this study was higher compared to studies in Malacca and Selangor by Hamid et al. (2017) for both outdoor and indoor environment. In this context, Hamid and his co-workers only characterised the PAHs that bounded to the gaseous samples. The contribution of low molecular weight (LMW) PAHs in gaseous samples towards $\sum$ PAHs was more dominant compared to high molecular weight (HMW) PAHs. This finding was supported by Pratt et al. (2018) (United State of America), Kim et al. (2012) (South Korea) and Masih et al. (2012) (India). However, in the particulate phase, the contribution of HMW PAHs towards $\sum$ PAHs was more dominant. Their lower volatility made them contribute to the higher $\sum$ PAHs obtained.

\section{Individual PAHs Distribution}

In this study, Nap, Ace, and Acp were not detected in the $\mathrm{PM}_{2.5}$ samples. These compounds are low molecular weight (LMW) PAHs with two (Nap) and three aromatic rings (Ace; Acp). According to Omar et al. (2006), LMW PAHs are more volatile compared to high molecular weight (HMW) PAHs and in tropical environments, they tend to segregate between gas phase and particulate phase. Moreover, PAHs with the lower ring- number tend to exist in the gas phase, especially in the area with high ambient temperature like Malaysia (Oanh et al., 2000; Omar et al., 2002; Jamhari et al., 2014).

Figure 2 shows the distribution of detected individual PAHs in the $\mathrm{PM}_{2.5}$ samples for all sampling stations. The concentration of the PAHs ranged from 0.1 to $3.6 \mathrm{ng} \mathrm{m}^{-3}$. Overall, the result showed that the concentration of most individual PAHs was noticeably higher in outdoor than indoor environments. In each sampling station, HMW PAHs (BbF, BkF, BeP, BaP, Pery, Ind, BghiP and DBA) were dominant in $\mathrm{PM}_{2.5}$ compared to LMW PAHs (Nap, Ace, Acp, Flo, Phe, Ant, Flu, Py, BaA and Chr).

BghiP was the most abundant PAHs that ranged between 0.32 to $2.78 \mathrm{ng} \mathrm{m}^{-3}$, contributing up to $26.58 \%$ of $\sum$ PAHs. The abundance of BghiP, BbF, BaP and Ind in particulate samples indicated the vehicular emission. HMW PAHs usually formed during the process involving high temperature such as fuel combustion. Since all the sampling stations are located along the roadside, the contribution of vehicular emission towards the distribution of PAHs is high. On the other hand, the formation of LMW PAHs is associated with lowtemperature combustion e.g. wood burning (cited by Tobiszewski \& Namieśnik, 2012). 


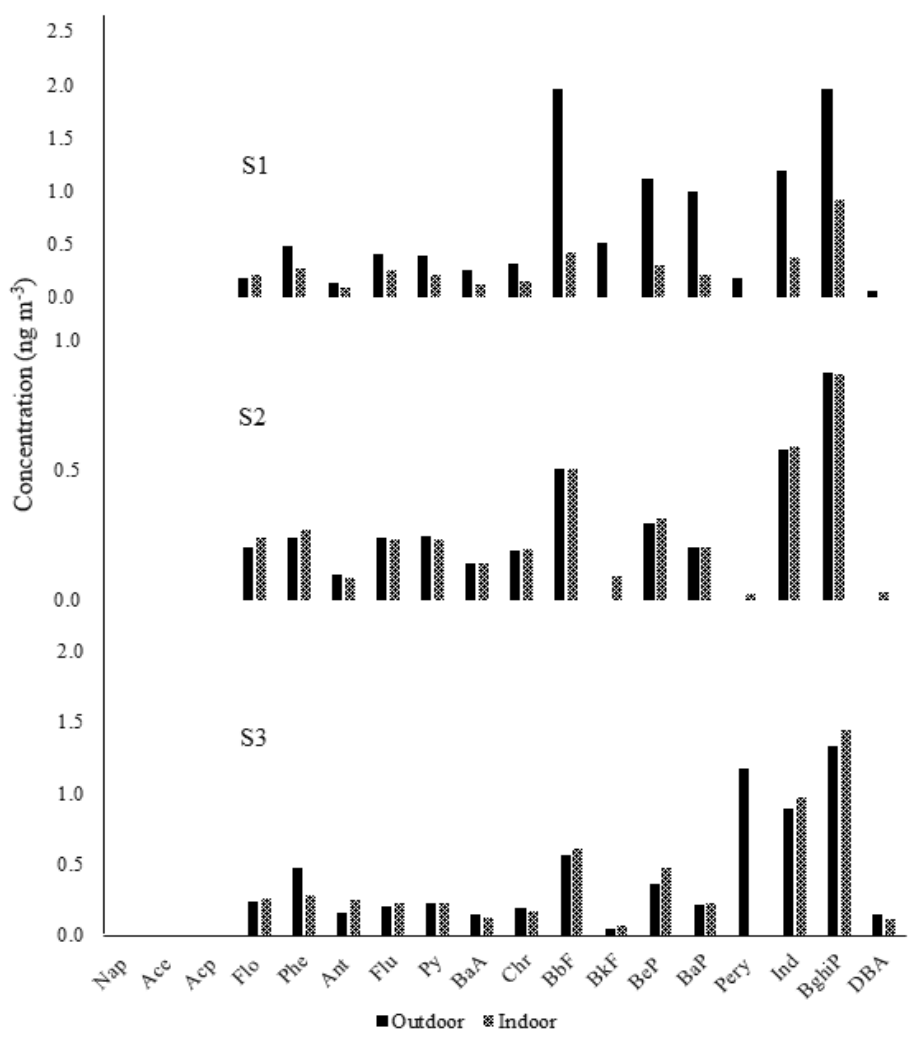

Figure 2 Distribution of individual PAHs in indoor and outdoor environment

\section{Source Identification}

For the purpose of source identification, the diagnostic ratios of a few selected PAHs with similar physicochemical properties were calculated. The ratios and their possible sources used in this study were based on a reported previous study by Ravindra et al (2008). By using diagnostic ratios, a few possible sources of PAHs in school environments could be identified. According to Tobiszewski and Namieśnik (2012), a comparison between pairs of PAHs with similar molar mass and physicochemical properties could help in determining the possible sources of PAHs as they might come from the same origin. Table 4 shows the average diagnostic ratios of PAHs at each sampling site along with the sources.

Table 4: Ratios of PAH at different monitoring schools

\begin{tabular}{lcccccc}
\hline \multirow{2}{*}{ Ratio } & \multicolumn{2}{c}{ S1 } & \multicolumn{2}{c}{ S2 } & \multicolumn{2}{c}{ S3 } \\
\cline { 2 - 7 } Ind/(ind+BghiP) & 0.94 & $\begin{array}{c}\text { Wood } \\
\text { Combustion }\end{array}$ & 0.4 & $\begin{array}{c}\text { Fuel } \\
\text { Combustion }\end{array}$ & 0.41 & $\begin{array}{c}\text { Fuel } \\
\text { Combustion }\end{array}$ \\
Bap/(Bap+Chr) & 0.67 & $\begin{array}{c}\text { Diesel } \\
\text { emission }\end{array}$ & 0.51 & $\begin{array}{c}\text { Diesel } \\
\text { emission }\end{array}$ & 0.38 & $\begin{array}{c}\text { Diesel } \\
\text { emission }\end{array}$ \\
Ind/BghiP & 0.65 & $\begin{array}{c}\text { Diesel } \\
\text { emission }\end{array}$ & 0.67 & $\begin{array}{c}\text { Diesel } \\
\text { emission }\end{array}$ & 0.69 & $\begin{array}{c}\text { Diesel } \\
\text { emission }\end{array}$ \\
Flu/Py & 1.14 & $\begin{array}{c}\text { Vehicular } \\
\sum \text { LMW/ }\end{array}$ & 1 & Vehicular & 0.98 & Vehicular \\
\hline
\end{tabular}

All the sampling stations are located in the Federal Territory of Kuala Lumpur which is a very heavily populated area. According to the Department of Statistic
Malaysia (DOSM), it was estimated that the number of population in Kuala Lumpur in 2017 was 1.79 million people (DOSM, 2018). The high number of population 
will increase the traffic densities of the study areas therefore, will contribute to the increase in the concentration of PAHs. A lot of vehicles can be found near the sampling stations as they are located along the roadsides. Besides, the vehicles used by the parents, teachers, and school buses are the potential contributors to the vehicular emission in school environments. This finding is in agreement with several previous studies that found vehicular emission is a major source of PAHs in PM especially in urban environments e.g. Chen et al., (2017), Jamhari et al., (2014) and Wang et al., (2017).

\section{Conclusion}

The results obtained from this study provide a baseline information on levels, distribution, and possible sources of PAHs bounded to $\mathrm{PM}_{2.5}$ in primary schools environments. To date, there is still limited data and literature concerning this topic especially in Malaysia. The present study revealed that the average total concentration of outdoor PAHs (3.8 to $10.1 \mathrm{ng} \mathrm{m}^{-3}$ ) was higher than indoor ( 1.6 to $8.0 \mathrm{ng} \mathrm{m}^{-3}$ ). The concentration of PAHs obtained at the schools in Kuala Lumpur was a reflection of the traffic densities in each sampling station. The high molecular weight PAHs with five to six rings contributed up to $80 \%$ of total PAHs. The abundance of $\mathrm{BbF}, \mathrm{BkF}$, Bep, Bap, BghiP and Ind suggested that PAHs originated from fuel combustion. Consequently, the results from diagnostic ratio analysis showed that PAHs bounded to $\mathrm{PM}_{2.5}$ in school environment in Kuala Lumpur came from pyrogenic process, with the vehicular emission as the most predominant sources of PAHs. Future study will be focusing on the detailed characterisation of PAHs bounded to $\mathrm{PM}_{2.5}$ in school environment as more sampling stations will be selected and the assessment of the carcinogenic risk due to the exposure of PAHs will be performed toward school children.

\section{Acknowledgements}

This study was supported by Central Laboratory Universiti Malaysia Terengganu, School of Environmental Science and Natural Resources, Faculty of Science and Technology, Universiti Kebangsaan Malaysia, and Ministry of Education.

\section{References}

Abdel-Shafy, H. I., \& Mansour, M. S. (2016). A review on polycyclic aromatic hydrocarbons: source, environmental impact, effect on human health and remediation. Egyptian Journal of Petroleum, 25(1), 107-123.

Amil, N., Latif, M. T., Khan, M. F., \& Mohamad, M. (2016). Seasonal variability of PM 2.5 composition and sources in the Klang Valley urban-industrial environment. Atmospheric Chemistry and Physics, 16(8), 5357-5381.
Barro, R., Regueiro, J., Llompart, M., \& Garcia-Jares, C. (2009). Analysis of industrial contaminants in indoor air: Part 1. Volatile organic compounds, carbonyl compounds, polycyclic aromatic hydrocarbons and polychlorinated biphenyls. Journal Chromatography A, 1216(3), 540-66.

Chai, Y., Kochetkov, A., \& Reible, D. D. (2007). The use of coarse, separable, condensed phase organic carbon particles to characterize desorption resistance of polycyclic aromatic hydrocarbons in contaminated sediments. Environmental Toxicology and Chemistry: An International Journal, 26(7), 13801385.

Chen, Y., Li, X., Zhu, T., Han, Y., \& Lv, D. (2017). $\mathrm{PM}_{2.5}$-bound PAHs in three indoor and one outdoor air in Beijing: Concentration, source and health risk assessment. Science of the Total Environment, 586, 255-264.

DOSM, Department of Statistic Malaysia. (2018). Federal Territory of Kuala Lumpur (Online).https://www.dosm.gov.my/v1/index.php?r =column/cone\&menu_idbjRIZX dnBueDJKY1BPWEFPRlhIdz09 [13th March 2018].

Hamid, H. H. A., Wan, L. W., Kai, I. P. R., Latif, M. T., \& Kannan, N. (2017). Distribution of Gas Phase Polycyclic Aromatic Hydrocarbons (PAHs) in Selected Indoor and Outdoor Air Samples of Malaysia: a Case Study in Serdang, Selangor and Bachang, Malacca. Environment Asia, 10(2). 80-85.

Hassanvand, M.S., Naddafi, K., Faridi, S., Nabizadeh, R., Sowlat, M.H., Momeniha, F., Gholampour, A., Arhami, M., Kashani, H., Zare, A. and Niazi, S. (2015). Characterization of PAHs and metals in indoor/outdoor $\mathrm{PM}_{10} / \mathrm{PM}_{2.5} / \mathrm{PM}_{1}$ in a retirement home and a school dormitory. Science of the Total Environment, 527, 100-110.

Jamhari, A. A., Sahani, M., Latif, M. T., Chan, K. M., Tan, H. S., Khan, M. F., \& Tahir, N M.(2014). Concentration and source identification of polycyclic aromatic hydrocarbons (PAHs) in $\mathrm{PM}_{10}$ of urban, industrial and semi-urban areas in Malaysia. Atmospheric Environment, 86, 16-27.

Khan, M. F., Latif, M. T., Saw, W. H., Amil, N., Nadzir, M. S. M., Sahani, M., Tahir, N.M. and Chung, J. X.(2016). Fine particulate matter in the tropical environment: monsoonal effects, source apportionment, and health risk assessment. Atmospheric Chemistry and Physics, 16(2), 597-617. 
Kim, J. Y., Lee, J. Y., Kim, Y. P., Lee, S. B., Jin, H. C., \& Bae, G. N. (2012). Seasonal characteristics of the gaseous and particulate PAHs at a roadside station in Seoul, Korea. Atmospheric Research, $116,142-150$.

Kim, K. H., Jahan, S. A., Kabir, E., \& Brown, R. J. (2013). A review of airborne polycyclic aromatic hydrocarbons (PAHs) and their human health effects. Environment International, 60, 71-80.

Mannino, M. R., \& Orecchio, S. (2008). Polycyclic aromatic hydrocarbons (PAHs) in indoor dust matter of Palermo (Italy) area: extraction, GC-MS analysis, distribution and sources. Atmospheric Environment, 42(8), 1801-1817.

Masih, J., Singhvi, R., Taneja, A., Kumar, K., \& Masih, H. (2012). Gaseous/particulate bound polycyclic aromatic hydrocarbons (PAHs), seasonal variation in North central part of rural India. Sustainable Cities and Society, 3, 30-36.

Mohammed, M. O., Song, W. W., Ma, Y. L., Liu, L. Y., Ma, W. L., Li, W. L., \& Wang, D. Z. (2016). Distribution patterns, infiltration and health risk assessment of $\mathrm{PM}_{2.5}$-bound PAHs in indoor and outdoor air in cold zone. Chemosphere, 155, 70-85.

Oanh, N. K., Reutergårdh, L. B., Dung, N. T., Yu, M. H., \& Yao, W. X. (2000). Polycyclic aromatic hydrocarbons in the airborne particulate matter at a location $40 \mathrm{~km}$ north of Bangkok, Thailand. Atmospheric Environment, 34(26), 4557-4563.

Oliveira, M., Slezakova, K., Delerue-Matos, C., do Carmo Pereira, M., \& Morais, S. (2016). Assessment of polycyclic aromatic hydrocarbons in indoor and outdoor air of preschool environments (3-5 years old children). Environmental Pollution, 208, 382-394.

Oliveira, M., Slezakova, K., Madureira, J., de Oliveira Fernandes, E., Delerue-Matos, C., Morais, S., \& do Carmo Pereira, M. (2017). Polycyclic aromatic hydrocarbons inprimary school environments: Levels and potential risks. Science of the Total Environment, 575, 1156-1167.

Omar, N. Y. M., Abas, M. R. B., Ketuly, K. A., \& Tahir, N. M. (2002). Concentrations of PAHs in atmospheric particles $\left(\mathrm{PM}_{10}\right)$ and roadside soil particles collected in Kuala Lumpur, Malaysia. Atmospheric Environment, 36(2), 247-254.

Omar, N. Y. M., Mon, T. C., Rahman, N. A., \& Abas, M. R. B. (2006). Distributions and health risks of polycyclic aromatic hydrocarbons (PAHs) in atmospheric aerosols of Kuala Lumpur, Malaysia. Science of the Total Environment, 369(1), 76-81.

Othman, M., Latif, M. T., \& Mohamed, A. F. (2016). The PM10 compositions, sources and health risks assessment in mechanically ventilated office buildings in an urban environment. Air Quality, Atmosphere \& Health, 9(6), 597-612.

Pratt, G. C., Herbrandson, C., Krause, M. J., Schmitt, C., Lippert, C. J., McMahon, C. R., \& Ellickson, K. M. (2018). Measurements of gas and particle polycyclic aromatic hydrocarbons (PAHs) in air at urban, rural and near-roadway sites. Atmospheric Environment, 179, 268-278.

Ravindra, K., Sokhi, R., \& Van Grieken, R. (2008). Atmospheric polycyclic aromatic hydrocarbons: source attribution, emission factors and regulation. Atmospheric Environment, 42(13), 2895-2921.

Romagnoli, P., Balducci, C., Perilli, M., Gherardi, M., Gordiani, A., Gariazzo, C., Gatto, M. P. and Cecinato, A. (2014). Indoor PAHs at schools, homes and offices in Rome, Italy. Atmospheric Environment, 92, 51-59.

Tobiszewski, M., \& Namieśnik, J. (2012). PAH diagnostic ratios for the identification of pollution emission sources. Environmental Pollution, 162, 110-119.

USEPA, United States Environmental Protection Agency. (2008) Code of Federal Regulations 40. Protection of Environment Revised July 1, Chapter IPart 423: Appendix A to Part 423-126 Priority Pollutants; 2008.

Wang, J., Xu, H., Guinot, B., Li, L., Ho, S.S.H., Liu, S., Li, X. and Cao, J., (2017). Concentrations, sources and health effects of parent, oxygenated-and nitrated polycyclic aromatic hydrocarbons (PAHs) in middle-school air in Xi'an, China. Atmospheric Research, 192, 1-10.

Xu, H., Ho, S.S.H., Gao, M., Cao, J., Guinot, B., Ho, K.F., Long, X., Wang, J., Shen, Z., Liu, S. and Zheng, C., 2016. Microscale spatial distribution and health assessment of $\mathrm{PM}_{2.5}$-bound polycyclic aromatic hydrocarbons (PAHs) at nine communities in Xi'an, China. Environmental Pollution, 218, 10651073. 